\title{
Biological features of egg productivity of black African ostriches under a semi-intensive keeping
}

\author{
N. Prokopenko*1, V. Melnyk ${ }^{1}$, S. Bazyvoliak ${ }^{1}$ \\ ${ }^{1}$ National University of Life and Environmental Sciences of Ukraine, \\ 15 Heroiv Oborony St., Kyiv, 03041, Ukraine, \\ *Corresponding author E-mail: NatPP@meta.ua \\ Received: 16.02.2021. Accepted 22.03.2021
}

\begin{abstract}
The study of egg-laying patterns and defining ways of increasing egg-laying productivity is a necessary condition for the development and increased efficiency of ostrich breeding. Therefore, some studies deal with egg productivity of ostriches of different age groups (group 1 - age 8-9 years, group 2 - age 4-5 years) for their long-term keeping under a semi-intensive system forest-steppe zone of Ukraine. The sex ratio in the families was 1:2-3. Behavioral patterns of poultry during the breeding season are close to natural ones. Older individuals are characterized with a longer productive period (January-October) than younger ones (March-September). According to the most extended daylight hours at this time of year, the higher level of egg-laying performance is established in May and summer months. The females' egg-laying performance analysis shows their significant individual features - 9-42 eggs were obtained from one female. It is worth mentioning that the productivity period's duration does not continuously regulate the number of eggs. There is a high positive correlation between the duration of the egg-laying process and total egg-laying performance in group $1(r=0.7981)$; in group 2 - there is no relation between these features $(r=$ 0.0843). The variability of egg-laying cycles of ostrich females has been confirmed, and it requires further studies. According to the intensity of lying during the breeding season, there are differences between younger and older poultry groups. The first two months and the last month of egg-laying are the least productive for all. It was established that the egg weight of older females is higher compared to young ones, with a potential difference between the groups ( $P>0.999)$ and a significant level of individual variability $(\mathrm{Cv}=1.78-8.06 \%)$. This indicates the necessity of successive work with the herd to optimize egg weight, as a significant variation in egg weight affects the duration of incubation and embryonic development of ostriches. It also leads to the elongation of the "hatch window" that causes heterogeneity of ostrich weight. New data allow characterizing the peculiarities of ostrich physiology, their ability to adapt to industrial conditions of breeding at farms located in the northern part of the forest-steppe zone of Ukraine.
\end{abstract}

Keywords: ostriches; system of keeping; egg productivity; age; breeding season

\section{Introduction}

At the current stage of poultry development, it is expected to increase the diversity of products using different poultry types. In recent years, rare and exotic poultry breeding, including ostriches, has become extremely popular. This is a promising and profitable business (Tereshhenko et al., 2008; Bychayev et al., 2017). People do industrial ostrich breeding and nurture in many countries worldwide (Vasylieva, 2009, Brassó et al., 2020). The ostrich organism's high adaptive capacities lead to broadening industrial breeding horizons (Horbanczuk, 2000; Perelman, 1996). The ostrich body adequately responds to changes in the functionality of physiological systems in line with the environment on the background of obtaining high-quality products (Goncharova, 2013). In Ukraine, about 60 farms are currently engaged in ostrich farming. The obtained scientific and practical experience allows different regions to organize efficient production and develop criteria for selecting ostriches, introducing effective production technologies.

It has been proved that keeping ostriches in poultry farms of different geographical areas impacts their biological characteristics. It is emphasized (Honcharova, 2012) that when breeding takes place in different geographical conditions, there is a restructuring of the whole link of physiological and biochemical processes in an ostrich body. Metabolic processes in its body adjust the organism's physiological state, particularly the stages of growth and development, homeostasis parameters. Thus, the mass of the African ostrich in nature is 90-100 kg, and when kept in captivity, they weigh 120-150 kg (Shanawany et al., 1999). Studies of keeping African ostriches in farms and zoos have shown (Strashniuk et al., 2014) that quantity and quality of feeding influence the intensity of growth and development, the level of reproductive qualities of poultry. Wild ostriches achieve their sexual maturity at 4-5 years (Reiner, 1995). Being raised on a farm, females lay their first eggs at 2-2.5 years, and males reach sexual maturity at three years. Under natural conditions, the female ostrich lays 12-18 eggs. Under farm conditions, young females lay 10-20 eggs during the first year, and in the following years, from 40 to 130 eggs per year, more often, it is about 40-60 eggs (Ipek et al., 2006). Egg-laying performance of ostriches of the same age, which are kept together in the herd under the same conditions, can vary from 20 to 60 eggs per breeding season (Lunling et al., 2004). The process of egg-laying depends on daylight. Accordingly, the geographical area also has an impact. The productivity season in ostriches can last from January-March to October, so it lasts 6-9 months. The length of the egg-laying period of females also varies. In Europe, the breeding season of ostriches lasts from March to late September, in South Africa lasts from June to 
late February-early March, and in Israel lasts from January to late August. In Poland, egg-laying peaks are in May and June, when the female produces $40-50 \%$ of annual egg production, including 10\% in August and 4-5\% in September (Horbańczuk, 2002). At many farms, adult ostriches are kept in conditions that are close to natural ones. A family of ostriches that consists of one male and several females is kept in a particular paddock (Beregovyi, 2012). One female is the dominant one. In the natural environment, she plays a unique role because she starts to lay eggs and then incubates them with the male in turns. Similar relationships are formed in other families.A significant number of factors influence the level of reproductive features of ostriches. The study of egg-laying patterns and the definition of ways to increase egg-laying productivity is a necessary condition for the development and efficiency of ostrich breeding. This determines the relevance of research on egg productivity of ostriches of different ages for their long-term semi-intensive system use in the forest-steppe zone of Ukraine.

\section{Material and Methods}

The research was conducted in Yasnogorodka ostrich farm LLC (Ukraine, Kyiv region, Makariv district). The farm has been working with a herd of black African ostriches since 2001. The first poultry was brought from Belgium and Denmark; the flock was completed with young stock from the Dnipropetrovsk region farm. Then the work was done with ostrich flock of own breeding. The individuals are kept in open-air cages and specialized poultry houses; the farm has its own hatching house. Feed recipes have been developed and approved for different age groups of ostriches, according to which feed is ordered and produced at the local feed mill. Two groups of birds were formed for the experiment: group 1 included three families of ostriches, in which the age of females was 8-9 years, with a sex ratio of 1:3 in two families and 1:2 - in one family; group 2 - includes three families of ostriches, in which the age of females was 4 5 years. The sex ratio in the families was the same as in group 1. The number of poultry in each group was three males and eight females. The conditions of nurturing experimental poultry complied with all standards of ostrich breeding. The sense of experiment was observing the behavior of poultry in families during the breeding season. We took into account the egg production of each female during the breeding season and determined egg weight. Based on individual egg productivity indicators, we establish egg-laying indicators and their intensity according to generally accepted formulas. It is essential that the livability of poultry during the study period was $100 \%$. Statistical processing of research results was conducted using MS Excel software.

\section{Results and Discussion}

Ostriches are polygamous, so there are several females per male in the family. At farms, ostrich families are formed with a ratio of males and females of 1:2 and 1:3. Analysis of the behavior of ostriches in groups allows identifying the dominant female in each family. The breeding season lasts from January to October. This is quite an extended period. Meanwhile, the female `s feathers darken before and during the egg-laying period feathers. For males, the indicator of readiness for reproduction is redness of the beak, eyelids, and legs. Observing ostriches' behavior allows us to identify male mating patterns concerning females in the family.

The analysis of the egg-laying performance of females shows their significant individual features (Table 1). Older females start the egglaying season in February-March, but in the group, there was a female (№5716), that began laying eggs in January. The egg-laying season of these females ended in August-October. The total duration of egg production was 7-9 months. Females of group 2 started egg-laying in March-April and ended in September. So group 2, if we compare with group 1, begins egg-laying later and all females stopped laying eggs in September. Thus, the duration of the season was 6-7 months (Figure 1).

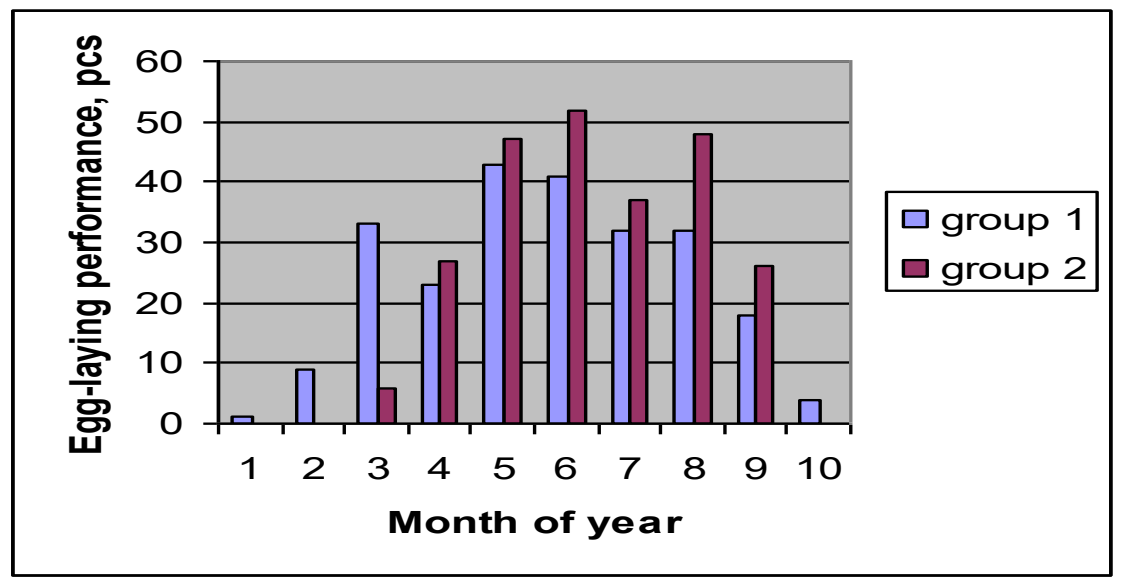

Fig. 1. Egg-laying performance of black African ostriches during the year, pcs.

Consequently, in older females, the productive period is longer. The higher level of egg-laying performance was established in May and summer months in line with the most extended daylight hours at this time of year.

Females of group 1 gave 9 to 42 eggs during the productive period. The variation by the family was $25.5-32.0$ eggs. On average, 29.5 \pm 2.65 eggs were obtained from one ostrich. We notice the high coefficient of variation of trait $-25.42 \%$, which was primarily caused by laying of females from family 3, especially females №5620 - its characteristics of laying.

The number of laid eggs in females of group 2 was 22-40. The variation by families was 24.7-34.5 eggs. On average, $30.4 \pm 1.76$ eggs were obtained per ostrich during the productive period $(C v=16.36 \%)$.

The difference in the average egg production of females of the two groups was only 0.9 eggs and was unreliable.

It is worth mentioning that the number of eggs is not always regulated by the productivity period's duration. A high positive correlation was established between the duration of egg-laying and total egg-laying performance in group $1(r=0.7981)$; in group 2 - a relation was not established between the signs $(r=-0.0843)$. 
Table 1. Egg-laying performance of black African ostriches.

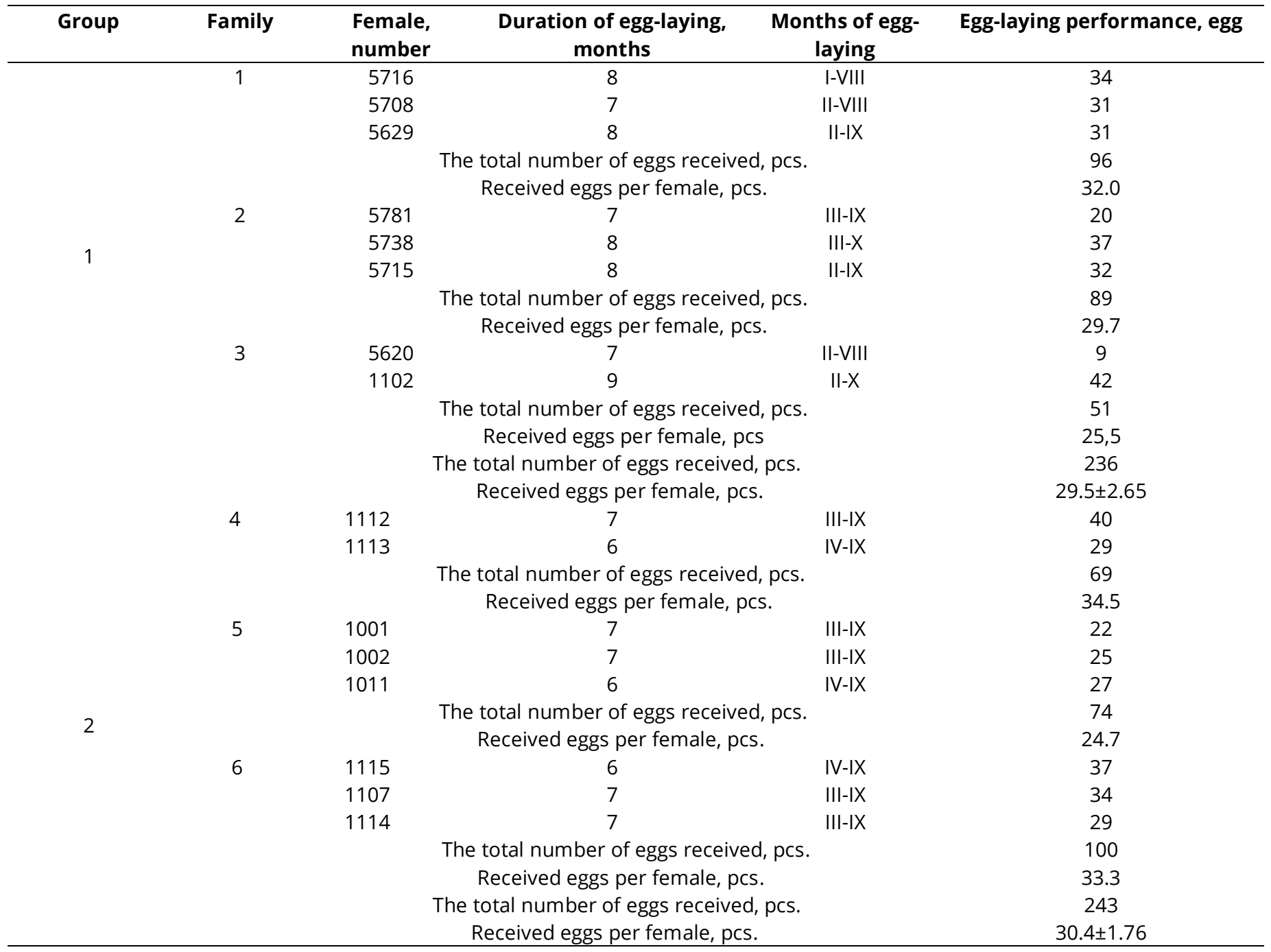

Table 2. The mass of ostrich eggs.

\begin{tabular}{|c|c|c|c|c|}
\hline Group & Family & Female, number & Mass of egg, $g$ & Cv, \% \\
\hline \multirow{8}{*}{1} & 1 & 5716 & $1342.4 \pm 33.83$ & 6.67 \\
\hline & & 5708 & $1432.1 \pm 9.64$ & 1.78 \\
\hline & & 5629 & $1371.5 \pm 39.07$ & 8.06 \\
\hline & 2 & 5781 & $1556.5 \pm 50.35$ & 7.92 \\
\hline & & 5738 & $1500.1 \pm 9.25$ & 1.74 \\
\hline & & 5715 & $1498.5 \pm 16.18$ & 3.05 \\
\hline & 3 & 5620 & $1466.2 \pm 37.96$ & 5.79 \\
\hline & & 1102 & $1440.4 \pm 21.02$ & 4.38 \\
\hline \multirow{10}{*}{2} & & By group & $1448.6 \pm 10,57$ & 5.56 \\
\hline & 4 & 1112 & $1421.6 \pm 10,55$ & 1.96 \\
\hline & & 1113 & $1425.8 \pm 22,66$ & 3.89 \\
\hline & 5 & 1001 & $1362.1 \pm 34,68$ & 6.74 \\
\hline & & 1002 & $1395.4 \pm 21,63$ & 4.10 \\
\hline & & 1011 & $1377.5 \pm 11,23$ & 2.00 \\
\hline & 6 & 1115 & $1375.7 \pm 14,74$ & 2.62 \\
\hline & & 1107 & $1335.3 \pm 19,75$ & 3.91 \\
\hline & & 1114 & $1320.9 \pm 37,33$ & 7.48 \\
\hline & & By group & $1375.9 \pm 7,66$ & 4.05 \\
\hline
\end{tabular}

Analysis of female egg production during the breeding season showed that 1-9 eggs were obtained from one ostrich of group 1 and 1 11 eggs of group 2 per month. The results are consistent with data (Kulikov et al., 2008; Sheldon, 2000) regarding female ostriches' laying during the breeding season. The female can lay 12-17 eggs a month, every two days. Mainly in the afternoon. The egg is formed in 44-48 hours. Egg-laying takes place in 2 cycles, sometimes in 6 ones. After each cycle, there is a break of 7-14 days. The reasons for the cyclicity of egg-laying have not been studied yet. Some females lay eggs in a short cycle (12 eggs per cycle) or those who do it in a long cycle (26 eggs per cycle). 
The analysis of the intensity of egg-laying performance showed differences between groups. Thus, females of group 1 reached the peak of egg production in May-June (27-30\%), group 2 - in June-September (30-37\%). Simultaneously, the first two and the last month of laying were the least productive for all.

In total, the laying curves of ostrich females differ from the general laying trend for birds. We consider it necessary to tell about the cyclical egg-laying of ostrich females during the breeding season. In this case, the individual characteristics of egg-laying are essential. At the next step of studies, the weight of eggs was evaluated (Table 2). A higher level of the indicator was established for older females $(1448.6 \pm 10.57 \mathrm{~g})$ than young ones $(1375.9 \pm 7.66 \mathrm{~g})$. The difference between the groups is $72.7 \mathrm{~g}$, or $5.28 \%$, and is reliable $(\mathrm{P}>0.999)$. The variation of the first group indicator is 1093-1705 $\mathrm{g}$, and in the second one - 1041-1510 g.

Analysis of females' egg mass showed a significant level of individual variability of the trait (CV = 1.78-8.06\%). With the average variation of the trait in the first group at the level of 5.56\% in females №5708 and №5738, the coefficient of variation of the trait was $1.78 \%$ and $1.74 \%$, respectively of the trait in females №5629 was $8.06 \%$. Among young females, the average variation of the trait is lower and amounted to 4.05\%. The minor variation was established in females №1112 - 1.96\% and №1011 - $2.00 \%$, the highest level of variation of the trait was found in females №1114 - 7.48\%. The correlation between egg weight and egg-laying performance level of females of group 1 is first of all harmful and quite significant $(r=-0.3122)$, but in the second group and in general, it was of low level and different direction (respectively $r=0.1880, r=-0.1884$ ). It requires further research and does not allow us to make definite conclusions.

\section{Conclusion}

Keeping ostriches on a farm is organized under a semi-intensive system in line with the sex ratio in families 1:2-3. Behavioral patterns of poultry during the breeding season are close to natural ones. Poultry of 8-9 years is characterized by a longer productive period (January-October) than a bird of 4-5 years of age (March-September). A higher level of egg-laying performance is established in May and summer months in line with the most extended daylight hours at this time of year. The analysis of the egg-laying performance of females shows significant individual characteristics. At the rate of laying 9-42 eggs in group 1, the trait variation was $25.4 \%$; in group 2 , it was received $22-40$ eggs with a variation of the trait of $16.36 \%$. The number of eggs is not always regulated by the duration of the productivity period. A high positive correlation was established between the duration of egg-laying and total egg-laying performance in group $1(r=0.7981)$; in group 2 - a relationship was not established between the signs $(r=-0.0843)$.

The analysis of female egg production during the breeding season showed that $1-9$ eggs were obtained from one laying individual of group 1 and 1-11 eggs of group 2 per month. The variability of egg-laying cycles of ostrich females has been confirmed, but it requires further study. According to the intensity of lying during the breeding season, there were some differences between younger and older poultry groups. Females of group 1 reached the peak of egg production in May-June (27-30\%), and group 2 - in June-September - 30$37 \%$. The first two and the last month of laying were the least productive for all. Compared to young poultry (1375.9 $\pm 7.66 \mathrm{~g}$, the level of egg weight of older females was higher $(1448.6 \pm 10.57 \mathrm{~g})$ with a potential difference between the groups $(\mathrm{P}>0.999)$. The egg weight analysis showed a significant level of individual variability of the trait ( $C V=1.78-8.06 \%)$. The obtained data showed the necessity for further work with the herd to optimize egg weight, as significant variation in egg weight affects the duration of incubation and embryonic development of ostriches, leading to elongation of the "hatch window" and causes heterogeneity of ostrich weight.

The obtained new data allows us to characterize the peculiarities of ostrich physiology, their ability to adapt to industrial breeding conditions in farms located in the northern part of the forest-steppe zone of Ukraine.

\section{References}

Berehovyi, V.K. (2012). Ostrich farming as a promising branch of animal husbandry. Agrosvit, 11, 29-32. [in Ukrainian].

Brassó, D. L., Béri, B., \& Komlósi, I. (2020). Studies on Ostrich (Struthio Camelus) - Review. Acta Agraria Debreceniensis, 1 , $15-22$. https://doi.org/10.34101/actaagrar/1/3772

Bychayev, A.G., Vasilyeva L.T. (2017). Ostrich in the modern world economy. Genetics and breeding of animals, 4, 42-49. [in Russian].

Goncharova, E.V. (2013). Potential capabilities and functional state of the ostrich body in industrial breeding. Retrieved from https://cyberleninka.ru/article/n/potentsialnye-vozmozhnosti-i-funktsionalnoe-sostoyanie-organizma-strausov-pri-promyshlennom-razvedenii/viewer [in Russian].

Honcharova, O.V. (2012). Physiological features of the ostrich organism under conditions of industrial breeding. Scientific Bulletin of LNU of Veterinary Medicine and Biotechnologies], 14 (3(2)), 35-38. [in Ukrainian].

Horbanczuk, J.O. (2000). Chow strusi. Warszawa: Megraf.

Horbañczuk J. O. (2002). The Ostrich. Warsaw, Poland. Polish Academy of Sciences Institute of Genetics and Animal Breeding.

Ipek, A., Sahan, U. (2006). Egg production and incubation results of ostrich farms in the Marmara region of Turkey. Arch. Geflügelk, 70 (2), 69-73.

Kulikov, L., Tjunina, T., Semchenko, A. (2008). Biological aspects of egg production of the African ostrich. Poultry, 2, 30-31. [in Russian].

Lunling, W., Yuanxing, Z., Wei, Z. (2004). The primary stagy on the stability of caring eggs of African black ostrich. International conference on development of ostrich estate. China. 10-15.

Perelman, B. (1996). Ostrich diseases of breeders. Ostrich Update, 3 (2), 49-51.

Reiner, G. (1995). Breeding and genetics. In G. Reiner, Ostrich Farm Management (pp. 71-92). Landwirtschftsverlag GmbH. Münster Hiltrup Auflage.

Shanawany, M. M., Dingle J. (1999). Ostrich Production Systems. Rome: Food and Agriculture Organization of the United Nations.

Sheldon, B.L. (2000). Research and development in 2000: directions and priorities for the World's poultry scientific community. Poultry Science, 79, 147-158.

Tereshhenko, A.V., Mikitjuk, D.N., Tagirov, M.T. et al. (2008). Breeding ostriches in Ukraine. Borki: Institut pticevodstva UAAN. [in Russian].

Strashniuk, D.V., Kyrychenko, R.M. (2014). Peculiarities of African ostrich breeding (Struthio Camelus) in the Polissya region of Rivne region. Scientific Issue Ternopil Volodymyr Hnatiuk National Pedagogical University. Series: Biology], 4 (61), 117-122. [in Ukrainian].

Vasylieva, O.O. (2009). Ostrich farming is a new promising branch of agricultural production in Ukraine. Bulletin of Poltava State Agrarian Academy, 1, 78-84. [in Ukrainian].

\section{Citation:}

Prokopenko, N., Melnyk, V., Bazyvoliak, S. (2021). Biological features of egg productivity of black African ostriches under a semi-intensive keeping. Ukrainian Journal of Ecology, 11 (2), Ecological Risk Assessment, 33-36.

\begin{tabular}{|l|l}
\hline$(\mathrm{cc})$ EY \\
EY
\end{tabular} 